\section{A shot in the dark}

\section{Fekri A. Hassan}

Centuries of Darkness. By Peter James. Jonathan Cape: 1991. Pp. 434. £18.

TIME has puzzled and intrigued thinkers for countless generations. For more than a century, historians and archaeologists have laboured to establish a credible chronology. Their passionately held notions of historical developments have been challenged by new discoveries and by contrary notions from colleagues working in other regions or motivated by different goals. The result has been a procession of new visions and revisions. In Centuries of Darkness, Peter James, in collaboration with four contributors (I. J. Thorpe, Nikos Kokkinos, Robert Morkot and John Frankish), presents a challenge to what has emerged in recent years as a synthesis of conventional views on world chronology from 1200 to $800 \mathrm{BC}$, the synthesis being the best of all possible worlds of controversial and contradictory data. The book may be disquieting for those who cherish the comfort of familiar schemes or find in conventional chronology a justification for their favourite or inherited notions of history. But to suggest, as James and his collaborators do, that an older generation of historians have closed minds is hardly a token of the veracity of this newer generation's claims. Their sensational tone and the ardency of their advocacy besmirches their scholarly efforts and poisons the air of reasoned scholarly exchanges. This is regrettable because James and his collaborators are professional archaeologists who raise many points worthy of critical examination.

The book purports to examine the chronology of numerous Mediterranean cultures (Italy, Greece, Cyprus, Crete, Palestine, Egypt and Nubia, Mesopotamia (now eastern Syria and Iraq) and Iran) to show that scholars have exaggerated the duration of a period referred to as the Dark Age in Greece. This period witnessed the Trojan wars, the expansion of Arameans, the age of the Ramessides, the transition to the Iron Age, the maritime commercial ventures of the Phoenicians and the spread of the alphabet. James and his collaborators work their way from one culture to another with a sledge-hammer, attacking any chronological scheme that does not fit their grand thesis. Amidst the rubble, they reach Egypt, which they regard as the benchmark for other chronological speculations.

We are thus bound to pay special attention to their proposal of a new Egyptian chronology. Doubts are indeed warranted in many cases. Nevertheless, they have not succeeded in hewing a foundation for an alternative firm chronology. In addition, their presentation of the calibrated radiocarbon dating for Egyptian eighteenth and nineteenth dynasties, curiously relegated to a footnote, does not instill confidence. Contrary to their claims, the calibrated radiocarbon dates from the Ramesside period (including an estimate of 1,230 \pm 96 calendar years for Ramesses II) are highly congruent with the conventional chronology for that time interval. Moreover, these dates are bolstered by the best radiocarbon age estimate in the Egyptian sequence - a series of highly consistent age measurements from Tell el-Amarna $(1,333 \pm 50$ calendar years $\mathrm{BC})$. This firm date provides a basis for accepting a conventional chronology for the Hittites and the Assyrians. It lends credence to the conventional correlation of Assuruballit, king of Assyria, mentioned in the Amarna letters, with Assuruballit I, contrary to the claims set out in the book. Also, if, as widely accepted, the interval between the Late Bronze and Early Iron Age in the Mediterranean is contemporaneous with the late nineteenth and early twentieth dynasties of Egypt, the former would date to about $1200 \mathrm{BC}$ as in the conventional chronology.

James and his colleagues are to be congratulated for the breadth of their treatment, but the reader should not expect new chronological findings or a methodological breakthrough. There is also no critical evaluation of traditional methods of dating using pottery style. Unfortunately, we still face the same chronological quagmire. The vagaries of the archaeological record and the subversion of chronological indicators by cultural processes (for example, the 'Doppler' effect in ceramics), and occasionally archaeologists themselves, have undermined the most ingenious chronological schemes. In addition, precise dates provided by classical writers appear deceptively accurate. Consequently, chronological estimates are inherently highly probabilistic and hence

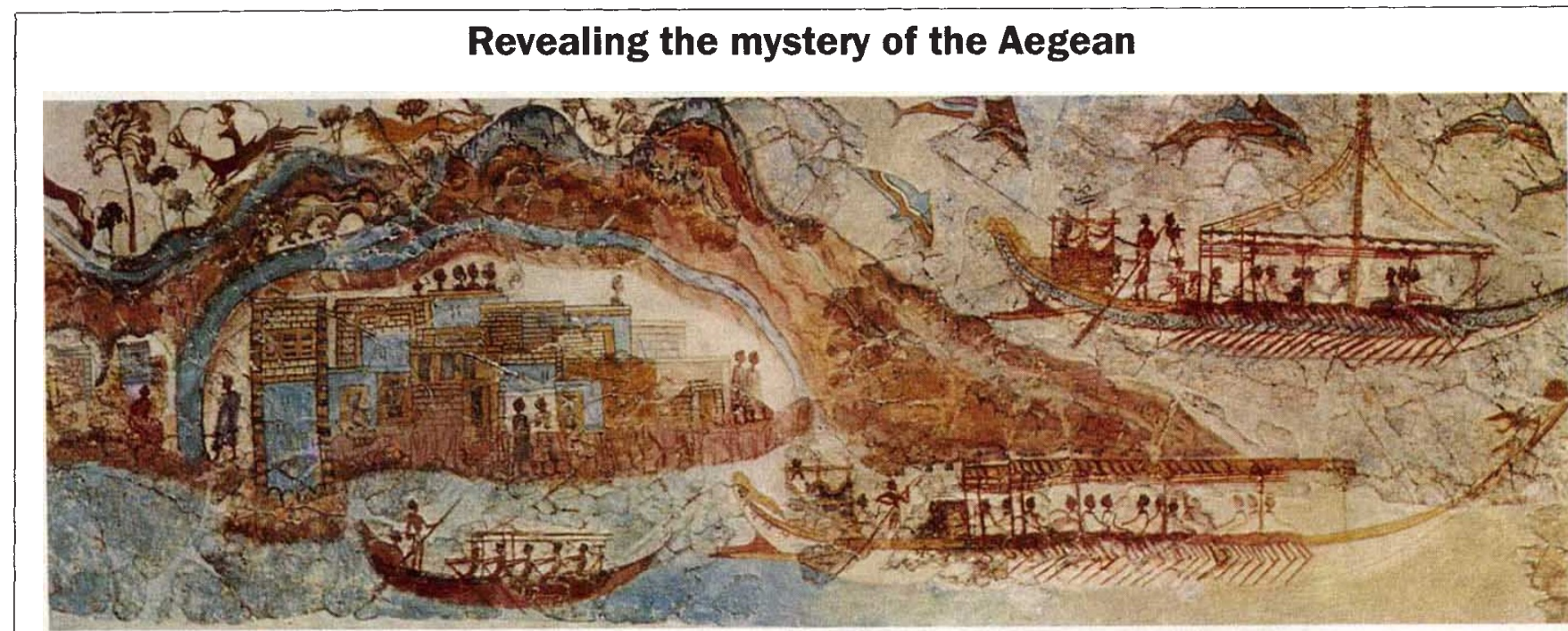

THE volcanic Santorini islands have fascinated scholars from the great Greek historian Herodotus to Duke Jacomo I Crispo of Naxos, the first to take a scientific interest in the islands. Study of the area has deepened over the past few decades thanks largely to three international congresses held to study the islands. The collected papers of the second congress, from which this fresco detail is taken, were published in 1978, and now three volumes of the third conference proceedings, Thera and the Aegean World, have recently been published by the Thera Foundation. Examining everything from Theran art, technology and volcanology to the 'Theran event and its global impact', these latest 'instalments' offer a wider analysis of this remarkable region, equated by some with the lost city of Atlantis. Further information available from the Thera Foundation, 105-9 Bishopsgate, London EC2M 3UQ, UK. 